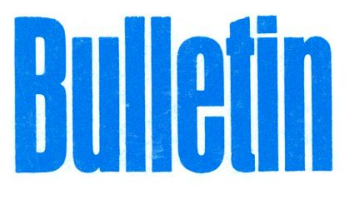

\title{
of the Americtill
}

Mélenrologitidal

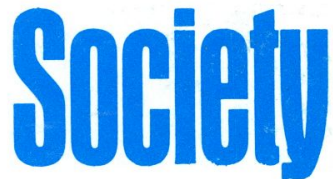

Volume 59 Number 1 January 1978

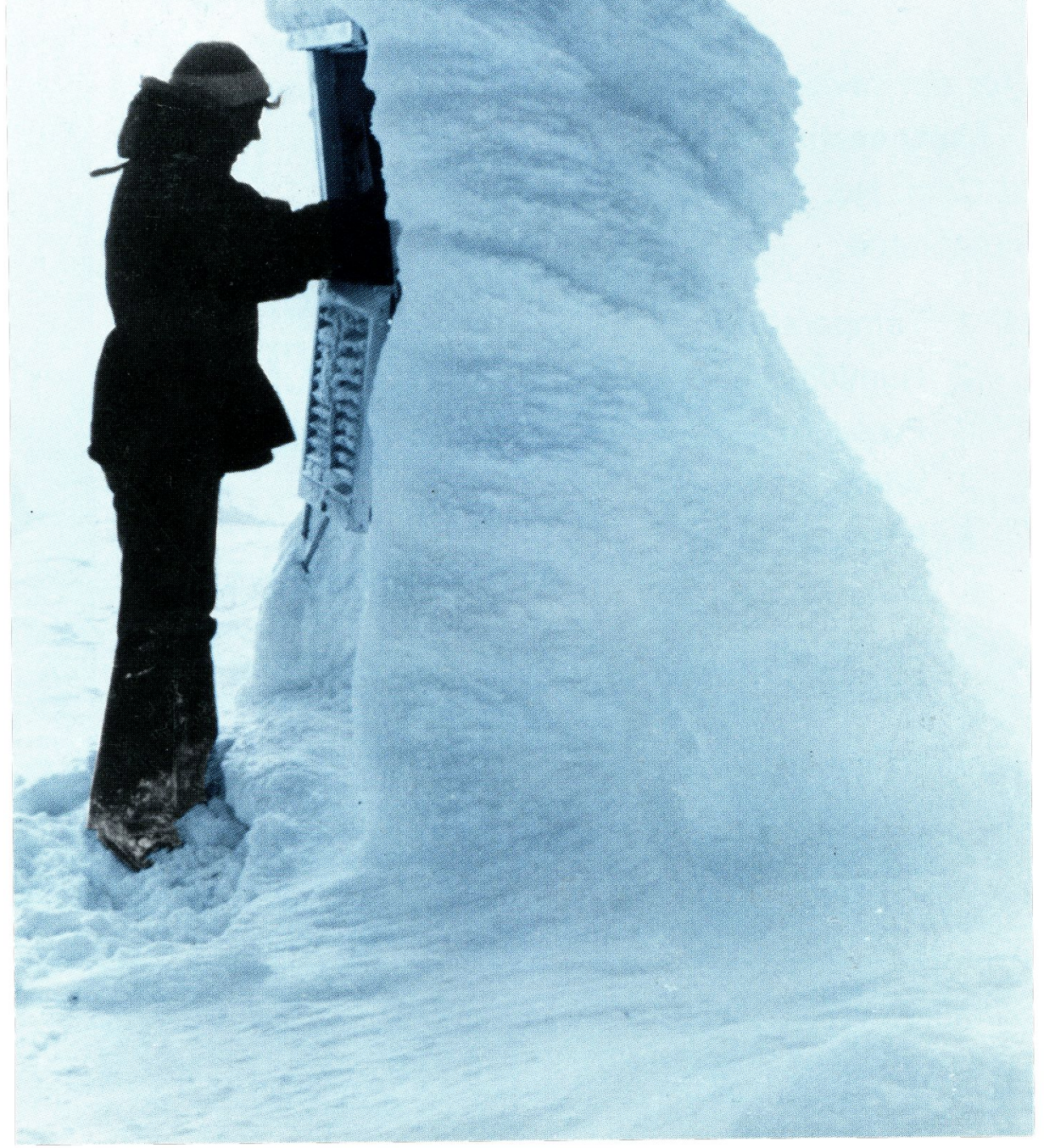




\section{ARE YOU ENERGY-ORIENTED?}

If you're looking for answers-in the wind, sun, or water-we can help you select instruments that will meet your technical specifications and your budget.

Write for our revised literature. Many sections-all part of Catg. No. 9-have been completed.

Sect. 1 Temperature

2 Humidity

3 Pressure

4 Wind

5 Precipitation

6 Solar Radiation

7 Upper Air \& Visibility

More sections are in preparation.

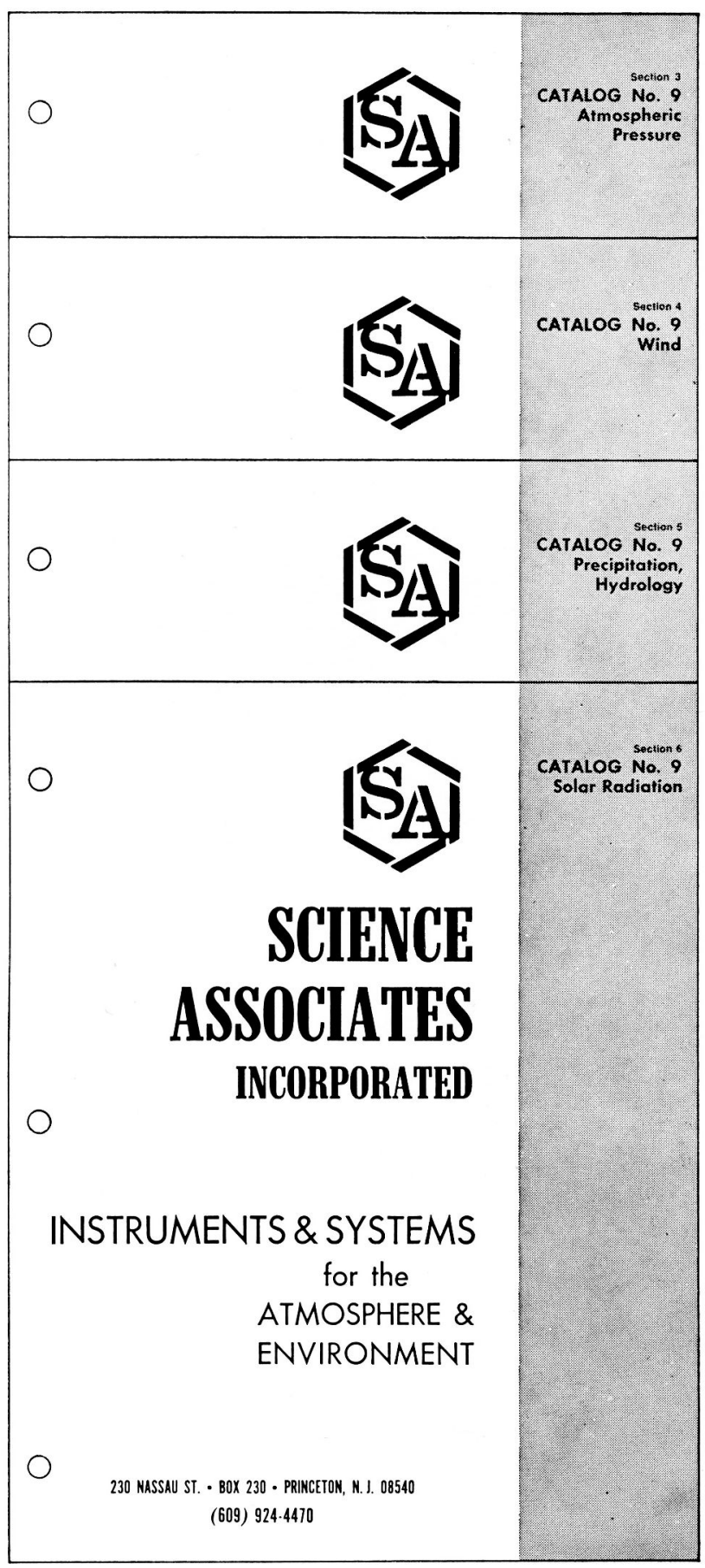




\section{We can't prevent this}

\section{œ.obut we can help you forecast it}

ALDEN FOFAX weather chart recorders aid prediction of pollution index... It is increasingly important to be able to predict atmospheric conditions which could lead to abnormally high pollution levels in a given area

Such predictions can be made more easily and with a higher confidence level by the use of information gathered by the National Weather Service and transmitted nationwide on the FOFAX circuit. Daily transmissions include two pollution potential charts in addition to long-range forecast information and photos from orbiting weather satellites.

ALDEN Series 1800 and 1100 Facsimile Recorders are the only fully automatic weather chart recorders specifically designed for operation on the FOFAX circuit. Simple, clean and quiet in operation ... no chemicals, powder or carbon paper. The wide dynamic tone shades of electrosensitive paper provide faster, easier visual interpretation.

For complete data write today, or phone collect and ask for Manager, Weather Systems Sales.

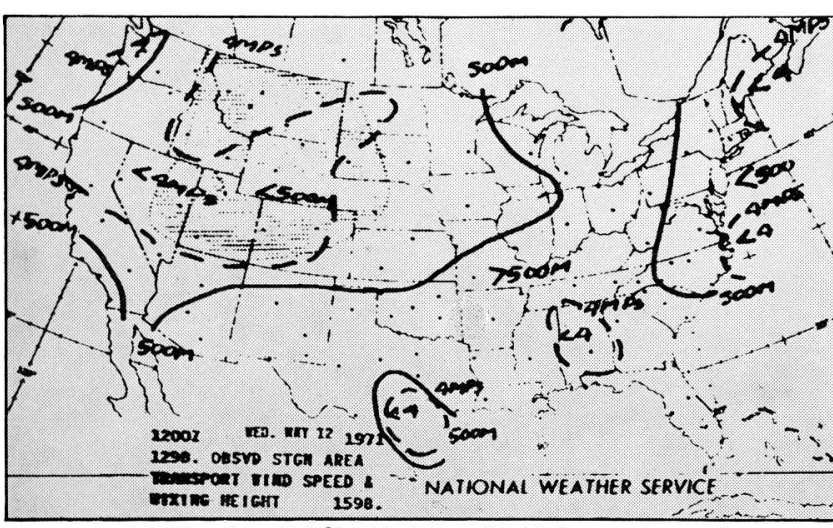

The above Pollution Potential Chart is transmitted twice per day on the

National Weather Service FOFAX Circuit and recorded on Alfax paper.

\section{ALDEN}

ELECTRONIC \& IMPULSE RECORDING EQUIPMENT CO. INC Washington St. Westboro.Ma 01581 (617) 3668851 TELEX 94.8404

$\square$ Please send your complete catalog

$\square$ Call me at once. My telephone number is

Send additional information on

$\square$ ALDEN 600 and 1100 WeatheRadar Recorders

$\square$ ALDEN 11 Auto-Select (APT/FOFAX/NAMFAX) Recorder

$\square$ ALDEN 18 Auto-Select FOFAX/NAMFAX Recorder

(MOMSS) Mode and Message Selection System

$\square$ ALDEN 11 and 18 Weather Chart Recorder (Standard networks)

\section{NAME}

COMPANY 


\section{Rainfall Measuring Instruments}

CAT. NO. 5-780

SERIES

UNIVERSAL

RECORDING

RAIN GAGES

Bulletin 76-3

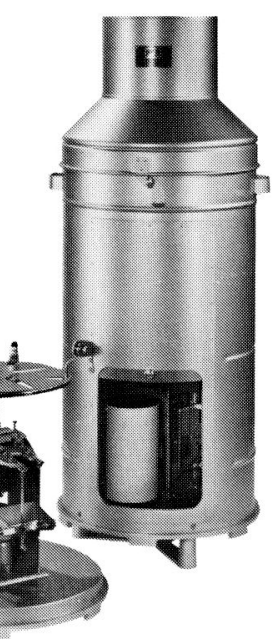

$1 / 2$ of $1 \%$ F.S. dual-traverse accuracy over $-40^{\circ}$ to $+125^{\circ} \mathrm{F}$

$6^{\prime \prime} \mathrm{ST}, 4.8^{\prime \prime}, 12^{\prime \prime}, 20^{\prime \prime}, 300 \mathrm{~mm}$, and $500 \mathrm{~mm}$ DT ranges

All but $5-780-20,-500 M M \ldots . . . \$ 435.00$ 5-780-20, -500MM w/overflow. . $\quad 480.00$ FOB Balto., Md.
HIGH-CAPACITY, RECORDING

PRECIPITATION GAGES,

CAT. NO. 6071 SERIES

Bulletin 76-80

$11.314^{\prime \prime} \mathrm{dia}$

teflon-

coated

collector

ruggedized

weighing

mechanism

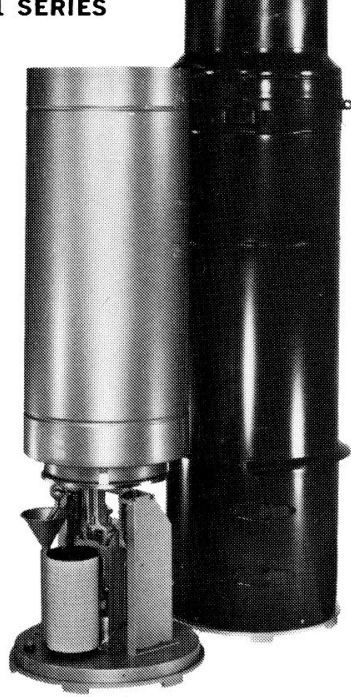

$30 "$ and $750 \mathrm{~mm}$ dual-traverse capacities $1 / 2$ of $1 \%$ F.S. accuracy, dual-traverse, over range of $-40^{\circ}$ to $+125^{\circ} \mathrm{F}$

$\$ 825.00$ Balto., Md
CAT. NO. 5-405

UNHEATED

AND

5-405HA

HEATED

TIPPING

BUCKET

RAIN

GAGES

Bullet in 76-44
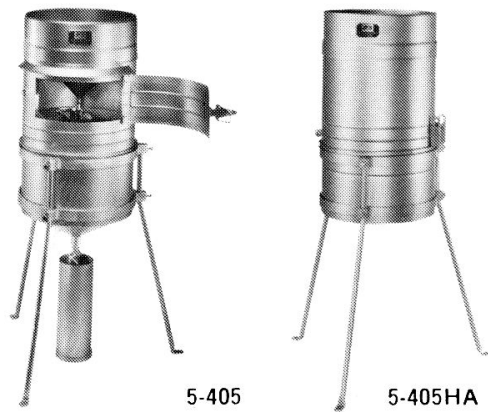

$1-6 \%$ accuracies over $1-6$ in. per hour rainfall rates

$0.01^{\prime \prime}$ and $0.2 \mathrm{~mm}$ sensitivit-are available

Cat. No. 5.405HA Rain Gages are insulated and heated for operation down to $-20^{\circ} \mathrm{F}$.

Cat. No. $5-405 \ldots . . \$ 425.00$ Cat. No. $5-405$ HA. $\quad 530.00$ FOB, Balto., Md.

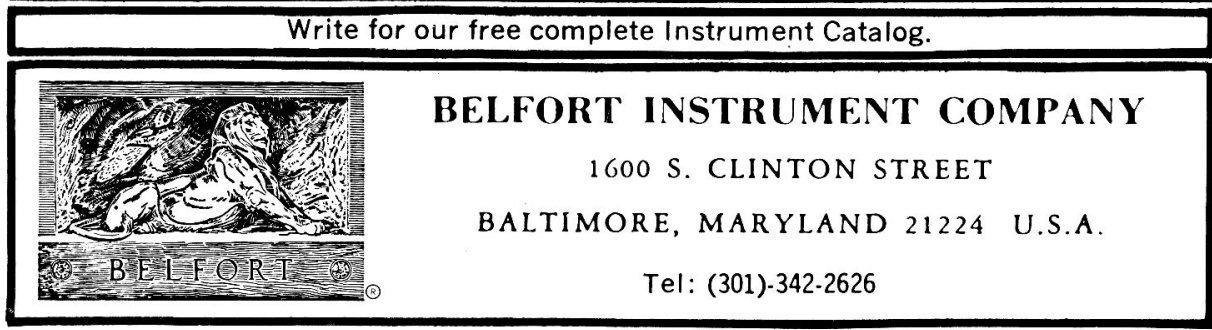



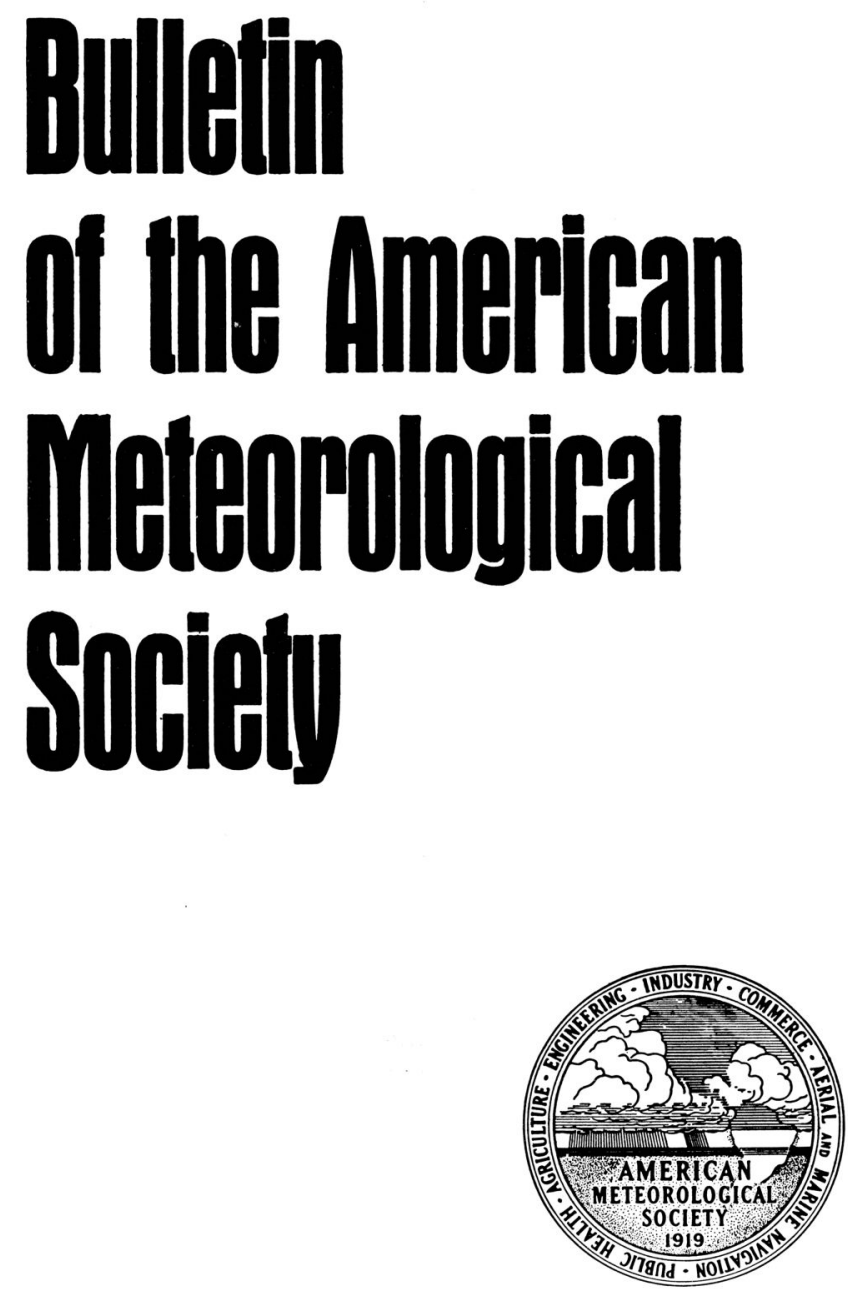

Volume 59

1978 
(C) Copyright 1978, American Meteorological Society. Republication, systematic reproduction, and other uses of any material in this journal, and the reprinting of figures, tables, abstracts, or other excerpts require permission or license from the American Meteorological Society. Individual readers, and nonprofit libraries acting for them, may freely use material in this journal only if the use is determined to be "fair use" under Section 107 or is permitted under the conditions specified in Section 108 of the U.S. Copyright Law (17 USC, as revised by P.L. 94-553). Permission to quote briefly from this journal in scientific works, with acknowledgment of the source, is granted. The appearance of the code and copyright notice at the bottom of the first page of an article in this journal indicates conditional consent by the American Meteorological Society that copies of the articles may be made for the personal or internal use, or for personal or internal use of specific clients; this consent is given on the condition, however, that the copier pay the stated per-copy fee through the Copyright Clearance Center, Inc., c/o Association of American Publishers, Inc. One Park Ave., New York, N.Y. 10016; this consent does not extend to other kinds of copying. Any contributions in this issue that do not bear their own separate AMS copyright notice either are exempted by the AMS from protection under its copyright or are U.S. Government works for which copyright protection is not available. 


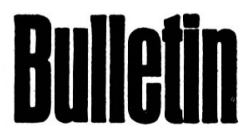

of the American Meteoplogiteal Socielly

Editor, Kenneth C. Spengler

Technical Editor

James E. Caskey, Jr.

Educational Affairs Editor

Owen E. Thompson

Focus on Forecasting Editor

Frederick Sanders

News Editor, Janet P. Dockery

Copy Editor, Reine Rosenbaum

Meetings Editor, Evelyn Mazur

Assistant Meetings Editors

Twila A. Bombard,

Kathleen L. Forrest

Advertising, Lilly G. Albo

The Bulletin of the American MeteoroLOGICAL SocieTY is the official organ of the Society, devoted to editorials, survey articles, professional and membership news, announcements, and Society activities. Editing and publishing are under the direction of Kenneth C. Spengler, Executive Director. Members are encouraged to send information to be considered for publication. Send four copies of each manuscript (text and illustrations). For guidance on preparation and style, see "Information for Contributors" on inside covers of a recent AMS research journal.

AMS Officers and Councilors: President, Werner A. Baum; President-Elect, George P. Cressman; Executive Director, Kenneth C. Spengler; Secretary-Treasurer, David F. Landrigan; Past Presidents, David Atlas and Charles L. Hosler, Jr.; and Councilors: Stanley A. Changnon, Jr., Neil L. Frank, Francis S. Johnson, Paul W. Kadlec, Albert J. Kaehn, Jr., Roy L. Leep, Jr., Margaret A. LeMone, Frederick P. Ostby, Jr., Norman A. Phillips, Frederick Sanders, Joanne Simpson, Robert W. Stewart, David K. Todd, Robert M. White, Jay S. Winston.

Published monthly by the American Meteorological Society at 45 Beacon St., Boston, Mass. 02108. Second-class postage paid at Boston, Mass., and at additional mailing offices. Subscription price to members is included in annual dues ( $\$ 20$ per year). Subscription price to nonmembers is available on request; single issues are $\$ 5$ each. Address all business communications, purchase orders, and inquiries to the Executive Director, American Meteorological Society, 45 Beacon St., Boston, Mass. 02108 (617-227-2425).
Volume 59, Number 1, January 1978

editorial

New Editors and Editorial Policy of the Monthly Weather Review D. R. Johnson

articles

Numerical Weather Prediction . . . . . . . . . . . F. G. Shuman

Further Outlook-Hazy . . . . . . . . . . . . . . . . . S. Ramage

Turbulent Flow in Two and Three Dimensions .......H. Tennekes

Potential Economic and Social Value of Short-Range Forecasts of Boulder Windstorms . . . . . . . . W. R. Bergen and A. H. Murphy

Sailplane Flights through Funnel Clouds ......... H. v. Senn

\section{GARP Topics}

Satellite-Tracked Drifters between Africa and Antarctica T. F. Harris and C. C. Stavropoulos

correspondence

Effect of the Severe Winter upon a Cooling Pond Fog Study J. D. Shannon and R. G. Everett

Distribution of the Tornado Threat in the United States

E. Kessler and J. T. Lee

program

Fourth Symposium on Meteorological Observations and

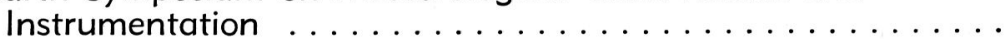

announcements 17

book reviews 63

news and notes 68

about our members 71

AMS announces undergraduate awards and scholarships .... 73 news from our chapters ...... 74 at $\mathrm{AMS}$ headquarters $\ldots \ldots \ldots 80$

AMS notice ........... 80

calendar of meetings ...... 83 contents of AMS journals ... 128 corporation members ....... 134 professional directory ..... 135 index to advertisers ........ 144

Cover photograph: This ice-covered instrument shelter illustrates the icing problems that the severe winter of $1976-77$ caused in a study of steam fog at a nuclear power station cooling pond complex in Dresden, Ill. For details, see correspondence by Shannon and Everett, which begins on page 160. (Photo by Gunther Zerbe.) 